\section{Intervening activity and the retention of meaningful verbal material ${ }^{1}$}

\author{
DONALD J. DILLON, New York State \\ Psychiatric Institute, 722 West 168 St., \\ New York, N.Y. 10032, and THOMAS F. \\ BABOR,2 Manhattan College, Riverdale, \\ N.Y. 10471
}

Twelve Ss learned three lists of 17 paired-associate English vocabulary items, and then relearned each list following $a$ period of normal activity, sleep, or sleep during which the lists were re-presented during the first hour of sleep. Retention scores were found to be significantly higher following sleep presentation than after sleep alone or after normal activity in two of the three measures of retention obtained, and all scores were higher than those usually reported. The meaningfulness of the situation together with the sleep re-presentation seemed to combine to induce a greater resistance to forgetting.

When periods of normal activity intervene between the acquisition and the retention of verbal material, there is interference with the memory consolidation and forgetting is great. If one allows sleep to intervene immediately after a learning session, there is less interference and forgetting is lessened. Among others, Jenkins \& Dallenbach (1924) and Gibb (1941) have demonstrated that retention following sleep is greater than retention following normal waking activity.

Some investigators have worked with sleep presentation and improved learning. Fox \& Robbins (1952) presented lists of 15 Chinese-English equivalents to three groups of sleeping Ss: a control group for whom music was played, a facilitated group who "heard" the correct list of equivalents for $29 \mathrm{~min}$, and an interference group which "heard" the paired associates in a mixmatched fashion. Fox and Robbins found that the facilitated group required fewer trials to learn the list than did the control group and that the interference group required more trials than did the control group. In other studies (Hoyt, 1953; Stampfl, 1952) sleep learning was not found to be more efficient.

Simon \& Emmons (1955) critically reviewed the literature on sleep learning, and (1956) failed to find sleep learning when EEG showed that the material was presented while alpha rhythm was absent. Portnoff, Backland, Goodenough, Karacin, \& Shapiro (1966) awakened Ss, delayed the onset of non-REM sleep and showed greater retention.

\section{METHOD} (range: 2-7). that greater amounts of delay resulted in

It seemed to these authors that the later studies dealing with sleep and learning have not been connected fully with the earlier studies. The Jenkins-Dallenbach results have held up with time, so the lack of interference seems to be a reasonable explanation. However, much of the sleep-learning research has dealt with the presentation of new and unfamiliar material, often of the nonsense variety, and the subsequent effects upon acquisition. One unanswered question concerns the effect on subsequent tests of retention of presenting previously learned material to sleeping Ss. The natural hypothesis would be that such re-presentation would result in greater retention. In view of the influence of meaningfulness on verbal leaming and retention, the authors also felt that meaningful English words, rather than nonsense syllables, should be employed, mostly for reasons of motivation.

The Ss were 12 male college juniors and seniors, born in the U.S. and 20 or 21 years of age. None had previous experience in learning experiments, and all volunteered to participate in the three experimental sessions. There were three lists of 17 paired-associate English vocabulary items. 3 The stimulus member was a familiar English word or two-word phrase that defined the unfamiliar response word. The lists were equated for frequency of recognition (less than 2 of the 17 items) in a college population and for the distribution of syllables per response word

The stimulus-response pairs were presented via tape (Recordio Corporation tape recorder, Model 602). S was seated $2 \mathrm{ft}$ from the tape recorder and listened to E's taped voice at a level of normal conversation. When the tape was played to a sleeping $\mathrm{S}$, the recorder was placed at a

\section{Table 1}

Means and Standard Deviations of Learning and Relearning Trials and of Measures of Retention Following the Three Kinds of Interpolated Activity. Data from $12 \mathrm{Ss}$.

\begin{tabular}{|c|c|c|c|c|c|c|}
\hline \multirow{2}{*}{\multicolumn{2}{|c|}{ Activity }} & \multicolumn{2}{|c|}{ Number of Trials } & \multirow{2}{*}{$\begin{array}{l}\text { Percent } \\
\text { Savings } \\
\end{array}$} & \multirow{2}{*}{$\begin{array}{c}\text { Number } \\
\text { of } \\
\text { Pairs } \\
\text { Recalled }\end{array}$} & \multirow{2}{*}{$\begin{array}{c}\text { Number of } \\
\text { Response } \\
\text { Words } \\
\text { Recalled } \\
\end{array}$} \\
\hline & & Learning & Relearning & & & \\
\hline w & $\begin{array}{l}\mathrm{M} \\
\mathrm{SD}\end{array}$ & $\begin{array}{r}10.0 \\
3.1\end{array}$ & $\begin{array}{l}4.5 \\
1.5\end{array}$ & $\begin{array}{r}54.3 \\
8.8\end{array}$ & $\begin{array}{l}5.3 \\
2.6\end{array}$ & $\begin{array}{l}8.7 \\
3.5\end{array}$ \\
\hline $\mathbf{S}$ & $\begin{array}{l}M \\
\text { SD }\end{array}$ & $\begin{array}{r}10.9 \\
3.1\end{array}$ & $\begin{array}{l}3.8 \\
1.0\end{array}$ & $\begin{array}{l}62.9 \\
14.2\end{array}$ & $\begin{array}{l}9.1 \\
2.2\end{array}$ & $\begin{array}{r}11.5 \\
1.9\end{array}$ \\
\hline SP & $\begin{array}{l}\text { M } \\
\text { SD }\end{array}$ & $\begin{array}{r}11.1 \\
3.5 \\
\end{array}$ & $\begin{array}{l}3.3 \\
1.5 \\
\end{array}$ & $\begin{array}{l}69.8 \\
11.7\end{array}$ & $\begin{array}{l}8.9 \\
2.3 \\
\end{array}$ & $\begin{array}{r}13.3 \\
2.3 \\
\end{array}$ \\
\hline
\end{tabular}

distance of $2 \mathrm{ft}$ from his head, and the tape played at a level of whispered conversation in order to avoid awakening.

PROCEDURE

Each list of paired associates was learned and then relearned $8 \mathrm{~h}$ later, after a period of interpolated "activity." Each S undertook the learning of all three lists in three separate sessions, with an intersession interval of 2 weeks and each session involving a different type of activity. The lists were presented in a predetermined order (Latin square) corresponding to the type of activity [waking (W), sleeping (S) and sleep presentation (SP)]. Two Ss were assigned at random to each of the six redetermined orders of presentation.

A variant of the alternate study-recall method was employed in which the learning trials consisted of alternate presentations of the 17 stimulus-response pairs and presentations of stimuli only. When the stimulus members were presented alone, $S$ was to supply the correct response before the next stimulus would be presented. Learning was complete when all 17 responses were correctly supplied once. During relearning, $S$ was first asked to recall, in any order, as many pairs as he could and then asked to supply the correct responses when the stimulus words were presented alone. The regular learning procedure was then followed.

When normal activity (W) intervened between learning and relearning, $S$ learned the list at 9 a.m., followed his usual academic pursuits, and relearned at 5 p.m. When sleep (S) intervened, $S$ learned prior to retiring at midnight and relearned upon awakening the next morning at 8 a.m. For the sleep presentation (SP), E set up the apparatus, and left the room while $S$ retired. E returned quietly approximately 45 min later, satisfied himself that $S$ was indeed asleep (via the standard behavioral indices), started the tape, and continued to observe $\mathrm{S}$ for any signs of restlessness, at which he turned off the tape until quiet sleep returned, or of $S$ awakening, at which point the experiment terminated and $S$ was eliminated (only two Ss were eliminated). There were 17 presentations of the list. 
Table 2

Percent Forgetting, Measured in Three Ways, as a Function of Kind of Interpolated Activity

Measurement

\begin{tabular}{ccccc}
\cline { 3 - 4 } Activity & Savings & $\begin{array}{c}\text { Paired } \\
\text { Asso- } \\
\text { ciates }\end{array}$ & $\begin{array}{c}\text { Response } \\
\text { Words }\end{array}$ & Average \\
\hline W & 46 & 69 & 49 & 55 \\
S & 37 & 46 & 32 & 38 \\
SP & 30 & 48 & 22 & 33 \\
Average & 28 & 54 & 34 & \\
\hline
\end{tabular}

Retention was measured in three ways: percent savings, the number of S-R pairs recalled, and the number of cued responses recalled.

\section{RESULTS}

The three measures of retention and the number of learning and relearning trials are summarized in Table 1.

The lack of significant differences among the trials prior to interpolated activity indicates the equivalence of the lists for these 12 Ss. Analyses of variance of savings score, recall of pairs, and recall of response words were also carried out. In each case, the main variables were the order of testing (Latin square) and the type of interpolated activity, and the error term was the within-cell variance (Ss within groups). The effects of interpolated activity were significant in all three cases: savings, $F=5.91, \quad p<.05 ;$ paired associates, $\mathbf{F}=9.90$, and number of response words, $F=7.10$, both $p<.01$, $\mathrm{df}=2,18$. The order of testing had no effect.

Three two-way comparisons ( $t$ tests) were done for each measure of retention. In all cases, the mere introduction of sleep resulted in higher retention scores than did waking activity, and for both savings scores and number of response words recalled the re-presentation during sleep resulted in even higher retention scores.

The retention scores were converted to scores of forgetting and are summarized in Table 2. Clearly, both type of activity and method of measurement induced different rates of forgetting.

\section{DISCUSSION}

Clearly, the intervention of sleep immediately following the learning of new verbal material benefits retention. The benefit is even greater if the newly learned material is re-presented to $\mathrm{S}$ during the early part of a normal 8-h sleep period, as evidenced in two of the three measures employed. This reduced forgetting has been explained in the past by reference to interference theory (e.g., Underwood, 1966; Jenkins \& Dallenbach, 1924); sleep prevents the operation of interference in the form of new and/or constant learning and, according to the trace-consolidation concept of Müller \& Pillizecker (1900), ongoing activity would serve to inhibit the establishment of the neural analog of the learned association-the memory trace This "inhibition of interference" is in evidence when one sees the increased savings, and the increase in number of response words or paired associates recalled following both sleep and sleep "rehearsal."

McGeoch \& Irion (1932) cite data from Ebbinghaus (1913) showing approximately $35 \%$ savings in relearning nonsense syllables after a period of about $8 \mathrm{~h}$ of waking activity and $50 \%-60 \%$ after $2-8 \mathrm{~h}$ of sleep. Our data reveal savings of $54 \%$ after $8 \mathrm{~h}$ of normal activity and $63 \%$ or $70 \%$ following sleep or sleep-presentation. The higher percentages in this study would indicate a greater resistance to forgetting, induced by the meaningfulness of the material.

The variation of forgetting (retention) scores with different methods of measurement has been well documented (e.g., Luh, 1922). The high forgetting scores accompanying the paired-associates measurement were not unexpected, since Ss learned initially to produce the $\mathbf{R}$ words when the appropriate stimulus was pronounced and, presumably, were set to recall in this fashion.

Forgetting was least on two of the m e a sures fol1owing the sleep-presentation - to the point where only $22 \%$ of the response words were lost. Somehow, the re-presentation induced a condition in which the effects were something like overlearning, and Ss tended to manifest even greater degrees of resistance to forgetting. It is possible that the R-word set that was induced initially is a factor, but the savings score also showed lesser forgetting following the sleep presentation.

Beh \& Barratt (1965) conditioned Ss to respond to one tone and not to respond to another and found transfer when testing during Stage C sleep, i.e., Ss responded to a "meaningful" stimulus during sleep. They were also able to build in stimulus significance during Stage C (non-REM) sleep and have the significance transfer to the waking state. This is in line with earlier findings of Oswald, Taylor, \& Treisman (1960), who presented evidence that suggests that auditory discrimination involving limited cortical functioning is possible without cortical arousal and/or reemergence of alpha rhythms. It is possible that having built-in meaning, as in the current experiment, re-presentation of the material during sleep facilitated the consolidation of the memory trace by bringing about some limited cortical functioning and that this level of function was not sufficient to awaken the Ss.

Sleep in this experiment was defined behaviorally, rather than physiologically, primarily because of the lack of EEG monitoring devices. We felt, however, that the first step in demonstrating the effectiveness of re-presenting newly learned material during sleep could be best carried out (1) by using naive Ss (as to EEG-sleep studies), and (2) by maintaining conditions as close to normal routine as possible. We felt that the effect on retention should be demonstrated before attempting to specify the stages of sleep during the re-presentation of the newly acquired material and believe that the subsequent greater resistance to forgetting has been demonstrated.

REFERENCES

BEH, H. C., \& BARRATT, P. E. H Discrimination and conditioning during sleep as indicated by the electroencephalogram. Science, 1965, 147, 1470-1471.

EBBINGHAUS, H. Memory: $A$ contribution to experimental psychology. (Translated by H. A Ruger and C. E. Bussenius.) New York: Columbia University Press, 1913.

FOX, B., \& ROBBINS, J. The retention of material presented during sleep. Journal of Experimental Psychology, 1952, 43, 75-79.

GIBB, J. The relative effects of sleeping and waking upon the retention of nonsense syllables. Psychological Bulletin, 1941, 38, 734

HOYT, w. The effect of learning auditory material presented during sleep. Unpublished MA dissertation, George Washington University, 1953.

JENKINS, J., \& DALLENBACH, K. Oblivescence during sleep and waking. American Journal of Psychology, 1924, 35, 605-612.

LUH, C. W. The conditions of retention. Psychological Monographs, 1922, 31, No. 142. MCGEOCH, J. A., \& IRION, A. L. The psychology of human learning. New York: Longmans, 1932. P. 356

MÜLLER, G. E., \& PILZECKER, A. Experimentelle Beitrage zur Lehre vom Gedächtnis. Zeitschrift für Psychologie, 1900, 1, 1-288.

OSWALD, I., TAYLOR, A., \& TREISMAN, M. Discriminative response to stimulation during sleep. Brain, 1960, 83, 440-553.

POR TNOFF, G., BACKLAND, F. GOODENOUGH, D. R., KARACIN, I., \& SHAPIRO, A. Retention of verbal materials perceived immediately prior to non-REM sleep. Perceptual \& Motor Skills, 1966, 22 751-758.

SIMON, C. W., \& EMMONS, W. H. Learning during sleep? Psychological Bulletin, 1955, 52, 328-343.

SIMON, C. W., \& EMMONS, W. H. Responses to material presented during various levels of sleep. Journal of Experimental Psychology, $1956,51,89-97$.

STAMPFL, T. The effect of frequency of repetition on the retention of auditory material presented during sleep. Unpublished MA dissertation, Loyola University, Chicago, 1953.

UNDERWOOD, B. J. Experimental psychology. New York: Appleton-Century-Crofts, 1966. NOTES

1. These results were presented in a modified version of this paper at the Psi Chi convention at St. John's University, Jamaica, N.Y., in April 1966.

2. Now at the University of Arizona.

3. Copies of lists available from senior author on request. 